\title{
Entrevista a Tidy Arquitectos: Albert Tidy V. [AT] + lan Tidy V. [IT]
}

El concepto de síntesis, la conformación de un cuerpo a partir de la identificación y reconocimiento de las partes que permiten y definen su presencia, parece ser una idea reiterada a la hora de explicar y comprender ciertos procesos de ejecución y respuesta en el panorama arquitectónico contemporáneo.

La reducción de elementos, la eficiencia en el uso de éstos y la presencia de una idea conceptual que coordine y subordine el proceso de trabajo como tal, son síntomas inequívocos de este modo de operar.

La oficina de arquitectura «Tidy Arquitectos», encabezada por los profesionales Albert Tidy e lan Tidy, definen gran parte de su ejercicio profesional a partir de la búsqueda de una arquitectura de síntesis. En tal contexto y tratando de dilucidar las claves que nos permitan entender su particular manera de trabajar, revisaremos parte de su obra y conversaremos con ellos, reflexionando sobre tal proceso de síntesis, indagando hasta dónde puede llegar este planteamiento de reducción como herramienta de composición de un cuerpo arquitectónico.

El concepto de síntesis puede ser reconocido en varios elementos y planos de su obra: la elección material de turno, la organización espacial de la obra, su presencia como cuerpo total e incluso en aquellos detalles y terminaciones constructivas que definen su presencia. Inicialmente, nos gustaría saber: ¿En qué consiste y de qué manera se lleva a cabo este proceso de síntesis en el trabajo de la oficina?

[IT]: Generalmente nuestro método tiene su punto de partida en el «lugar». Como primera acción elegimos una respuesta a las miles de posibilidades que propone el contexto. En este sentido la elección es determinada por la omisión de factores que consideramos más débiles y por la exacerbación o reforzamiento de los que consideramos más relevantes e interesantes. De esta manera se da inicio al proceso de síntesis, el que luego se traduce en respuesta formal.

[AT]: La operación de reducción consiste en algo parecido al juego de la yenga: debes sustraer lo que más se pueda antes de que la torre, o en este caso la idea, se desplome. Generalmente nuestros proyectos se alejan de esta aspiración por las naturales debilidades plásticas a las que sucumbimos en el trayecto sin embargo, existe en nuestro trabajo la persistente búsqueda para hacer que la arquitectura -entendida como un fenómeno complejo-, resulte expuesta en la lectura como algo fácil, es decir de lectura instantánea. En este sentido empleamos el artificio como recurso para ocultar aquello que nos resulta de poco interés como lo es la complejidad gratuita.

Al aproximarnos a sus obras, nos parece distinguir que la expresión material de aquel inicial proceso de síntesis se materializa en la idea de "un cuerpo». Presencia que entendemos distinta a una forma, volumen o elemento, pues sin duda un cuerpo resulta algo más complejo en tanto actúa como contenedor. ¿A qué se refieren cuándo denominan a su obra como «cuerpo»?

[AT]: El proceso de síntesis lo entendemos como la operación forzada de integrar las diversas variables de un determinado problema arquitectónico en un diagrama. El resultado formal de este diagrama es lo que entendemos por cuerpo. La exploración libre de la forma es un aspecto que consideramos ajeno a nuestro interés.

[IT]: Creemos en la potencia de la forma como medio de expresión de la idea. De esta manera, el concepto de "potencia»lo entendemos como el resultado de partes coordinadas para lograr un objetivo común.

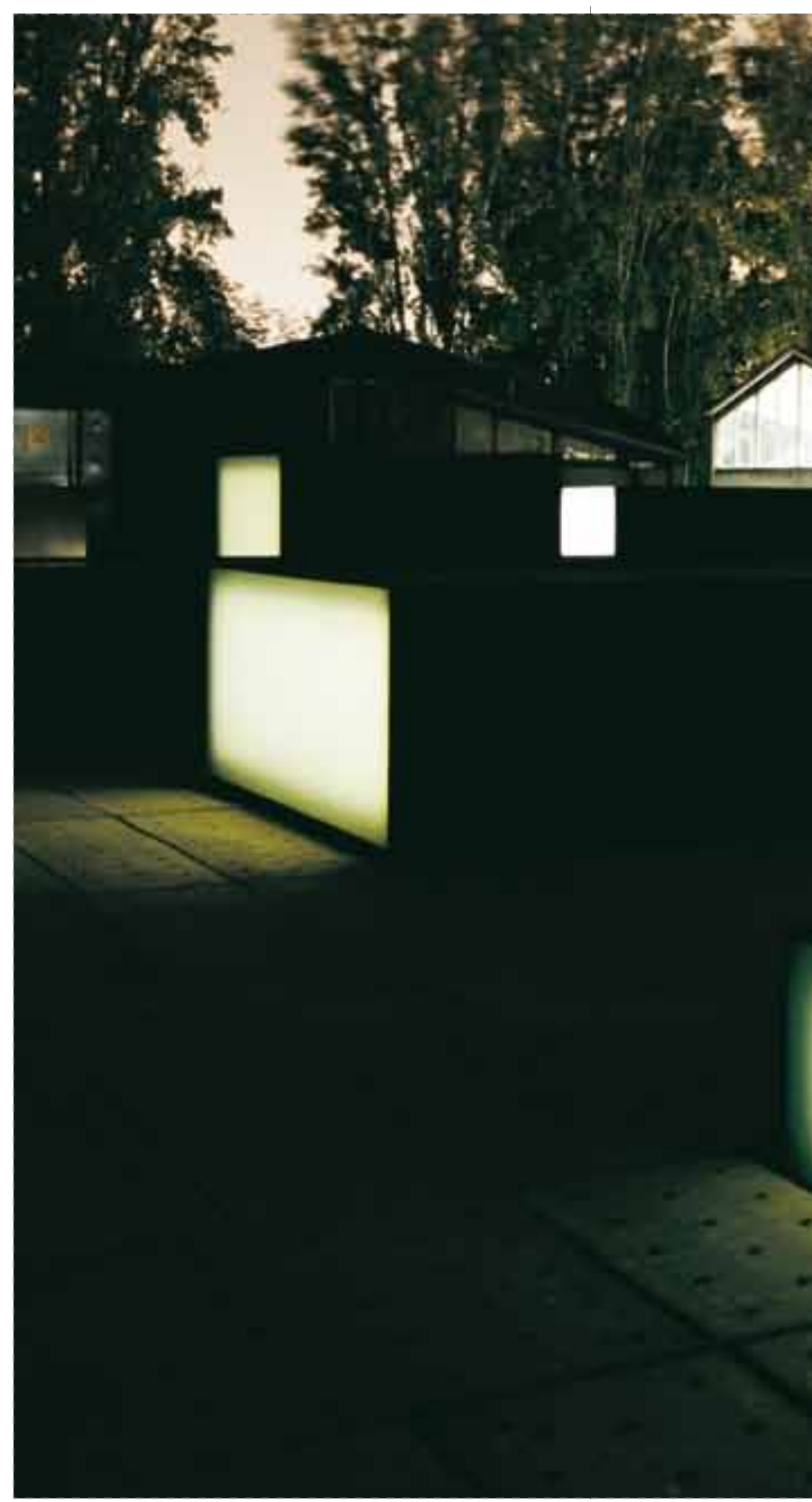


Colegio San Sebastián de Melipilla. Ian Tidy + Albert Tidy + Cecilia Aldunate, año construcción 2009 (fotógrafo: Ian Tidy)
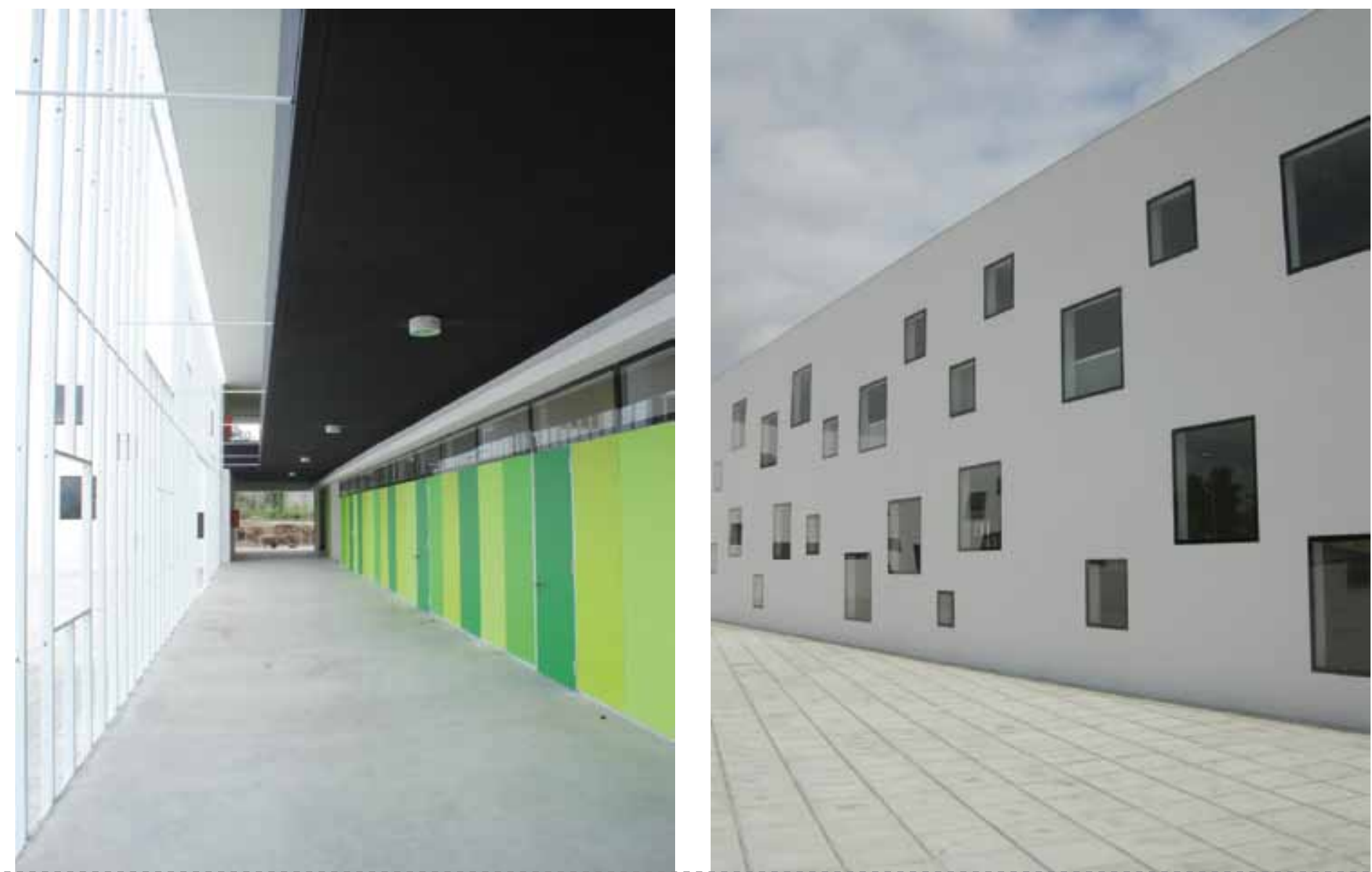

Finalmente, la supresión de cualquier discurso paralelo da lugar a la forma como cuerpo.

Siguiendo con la idea anterior, la presencia de este cuerpo como contenedor. ¿Cuál es el contenido de este contenedor, cuáles son las características de este contenido? Contenido que en arquitectura es asociado al concepto de espacio.

[AT]: El cuerpo arquitectónico tiene la doble capacidad de comunicar hacia el exterior y hacia el interior, entendiendo la primera instancia como el impacto público y la segunda como la experiencia espacial. Si bien estos discursos pueden ser coherentes, distintos o deliberadamente contrapuestos como parte de una idea generatriz, también existen de manera disociada, como ocurre generalmente con los proyectos de arquitectura interior, donde el contenedor es dado y generalmente rígido como variable.

[IT]: Si bien funcionalmente cada obra contiene un programa espacial, lo que más nos interesa es que contenga un significado. Por ejemplo, si queremos que una obra se "asome» hacia el paisaje, los recintos interiores deben recoger esta idea a través de las vistas. Así, el significado se manifiesta tanto en su respuesta formal exterior, como en la relación de dichos espacios interiores con los exteriores (cercanos y lejanos), respondiendo a las características del entorno y las necesidades del encargo.

Si analizamos su obra, podemos pensar que el cuerpo arquitectónico al que hacen referencia, presenta una condición expresiva previa, definida a priori en el mencionado proceso de síntesis y que no necesariamente es la misma que la naturaleza de los materiales empleados para la construcción de la obra. ¿Cómo se lleva la búsqueda de un cuerpo que impone su condición expresiva incluso frente a las posibilidades de materialización aportadas por las características propias de los materiales utilizados en su construcción?

[IT]: Es cierto que muchas veces la elección del material se encuentra supeditada a la acción formal o expresiva de lo que se quiere lograr. En este sentido la elección del material a utilizar será el más apropiado y económicamente viable para lograr reforzar la idea generadora.

Sin embargo, no siempre es así, ya que también hemos hecho el ejercicio inverso. Por ejemplo la casa Di Pede-Marshall tomó su expresión plástica desde el material escogido y a su vez la elección del material tuvo que ver con los colores del entorno.

[AT]: No existe un momento específico en el proceso de diseño para definir la materialidad a utilizar. A veces parte desde la obsesión con algún material específico, como es el caso de la casa Martínez y la clara referencia a la expresión del pliegue presente en el trabajo de Tony Smith ${ }^{1}$ (claramente no habríamos llegado a una síntesis plástica con otro material que no fuese el acero en planchas, ya que

Tony Smith (1912-1980). Escultor, artista visual, y teórico del arte norteamericano cercano al minimalismo. 


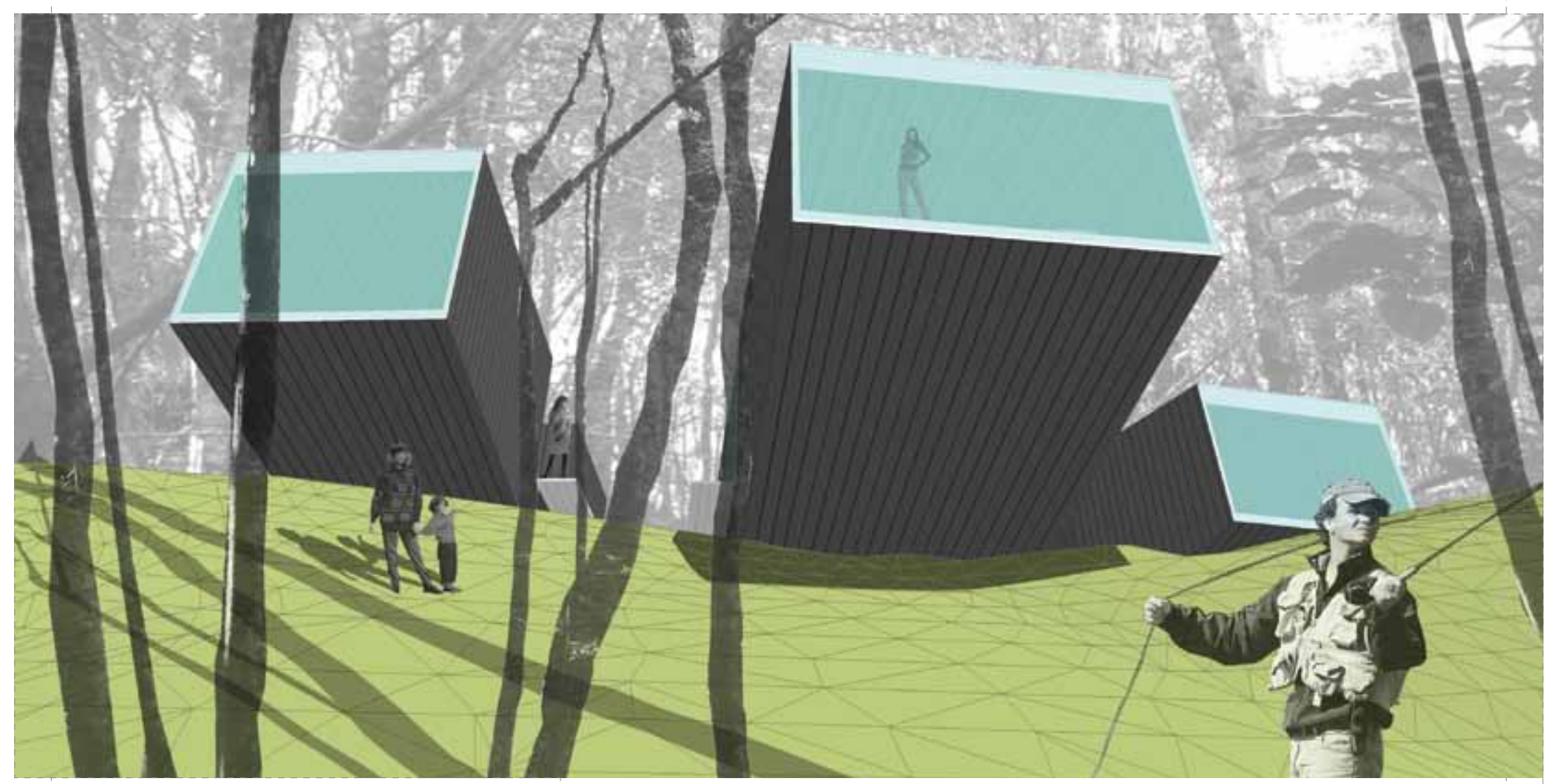

las soluciones constructivas habrían sido más tradicionales). En otras oportunidades el material se relaciona con el contexto inmediato y la estrategia a utilizar, como es el caso del proyecto para un pequeño hotel que estamos desarrollando en las cercanías de Pucón. En este caso nos interesaban dos cosas: que la construcción tuviera el menor impacto posible en el terreno, lo que determinó la utilización de estructuras livianas en acero que apenas se posaban en el terreno, y por otro lado la utilización de madera como revestimiento y estructura secundaria dada su disponibilidad en abundancia del lugar. Probablemente no habríamos logrado estructuras tan esbeltas sin el acero como estructura y ciertamente habríamos incrementado los costos de construcción utilizando un material distinto a la madera como revestimiento.

Sin lugar a dudas, la operación de síntesis permite la reducción de elementos de trabajo, de aquellas variables que condicionan y determinan la elaboración de un nuevo elemento o cuerpo. Pues bien tal disminución de variables permite suponer un menor grado de diferenciación entre una obra y otra, esto en un contexto donde la búsqueda de singularidad de la obra sigue presente como tema relevante en la

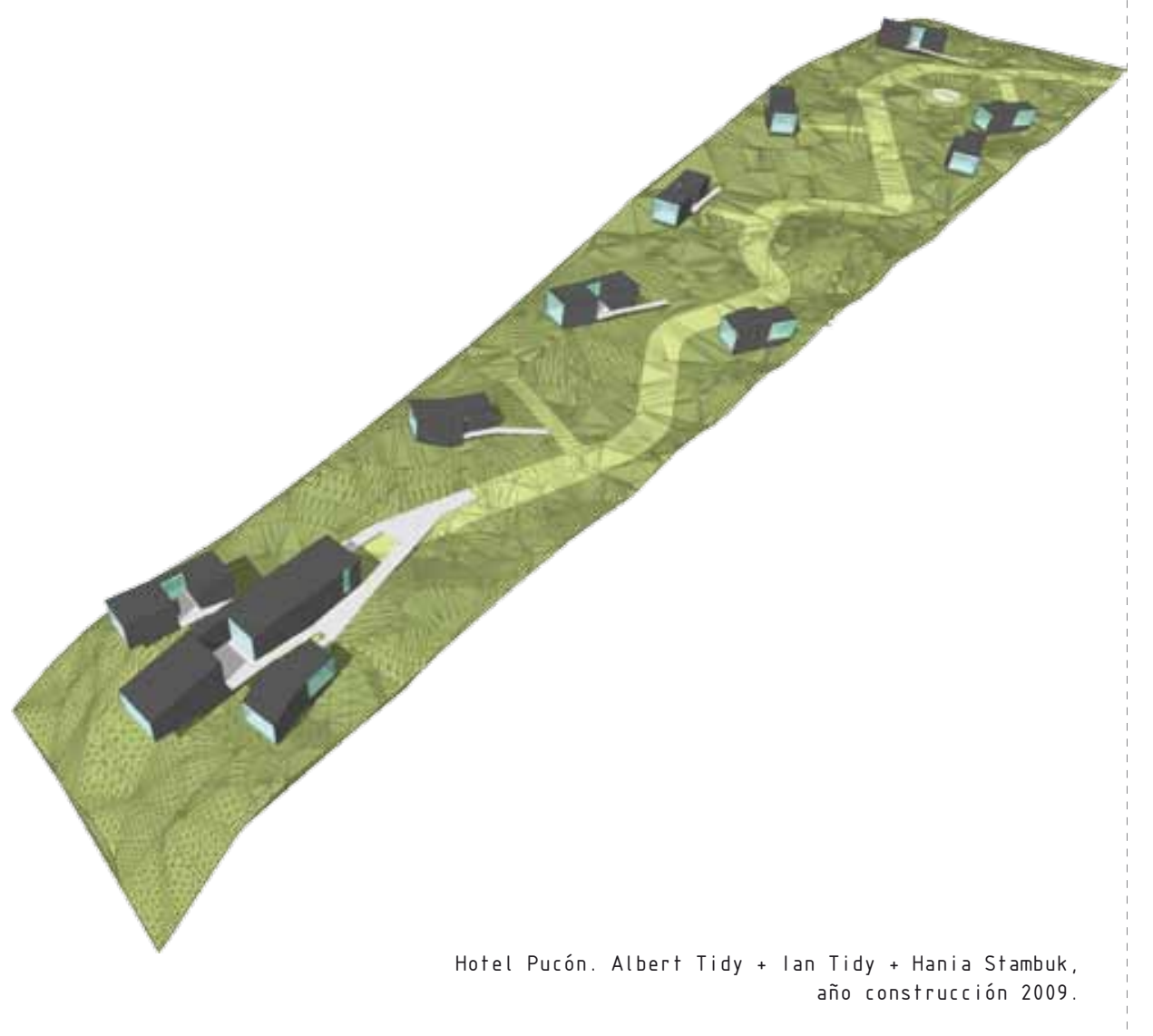


discusión arquitectónica. ¿Cómo se plantea la diferenciación y singularidad entre cada una de las obras ejecutadas por parte de la oficina?, ¿es una preocupación relevante en el trabajo de la oficina?

[AT]: Es nuestra preocupación que cada proyecto aporte algo nuevo: una materialidad, un detalle, una exploración plástica o algún invento, sin embargo nos resulta imposible desconectar un trabajo del anterior. La búsqueda no termina con el encargo. A veces pasan varios proyectos donde intentas hacer algo y no lo encuentras hasta varios años después, quizás en el tercer o quinto nuevo encargo. Cada proyecto es un intento. Pero entendemos ese intento como parte de un discurso del cual -consciente o inconscientemente- resulta difícil liberarnos. Los «tics» persisten. Algunos se mejoran. Otros se desechan, y pienso que finalmente la construcción de estas obsesiones en el tiempo puede llegar a conformar una expresión de identidad como resultado de aquella búsqueda.

[IT]: Singularidad no necesariamente quiere decir que cada obra deba ser opuesta o distinta a la anterior. Creemos en explorar distintas posibilidades de respuestas arquitectónicas para la diversidad de necesidades, sin embargo creemos vital lograr un discurso coherente a través de nuestra obra. En este sentido el oficio y la resolución de los detalles determinan un hilo conductor importante en cada obra sin necesidad de tener la misma respuesta formal. Ambicionamos que nuestro trabajo sea una representación de un pensamiento lúcido, en el que la complejidad constructiva quede oculta para facilitar la transmisión y comprensión del significado arquitectónico.

Si el contenido de este cuerpo, debido a las particularidades del encargo en cuestión, resultara más amplio o incluso más complejo, ¿qué ocurre cuando crece la escala de este cuerpo?, ¿hasta dónde es posible la operación de reducción?, ¿cómo se plantea finalmente este proceso de síntesis en tal condición?

[AT + IT]: Creemos que la complejidad del problema es inversamente proporcional a la escala. Diseñar un edificio puede ser más trabajo que diseñar una silla, pero diseñar una silla es infinitamente más difícil. E salar de Uyuni² -por ejemplo- es enorme,

El Salar de Uyuni, el mayor desierto de sal del mundo, con una extensión de $12.000 \mathrm{~km}^{2}$, está ubicado en Potosí, altiplano Boliviano.
Casa Müller Tunquén Albert Tidy + lan Tidy + Emil io Marín año 2003 (fotógrafo: Albert Tidy).
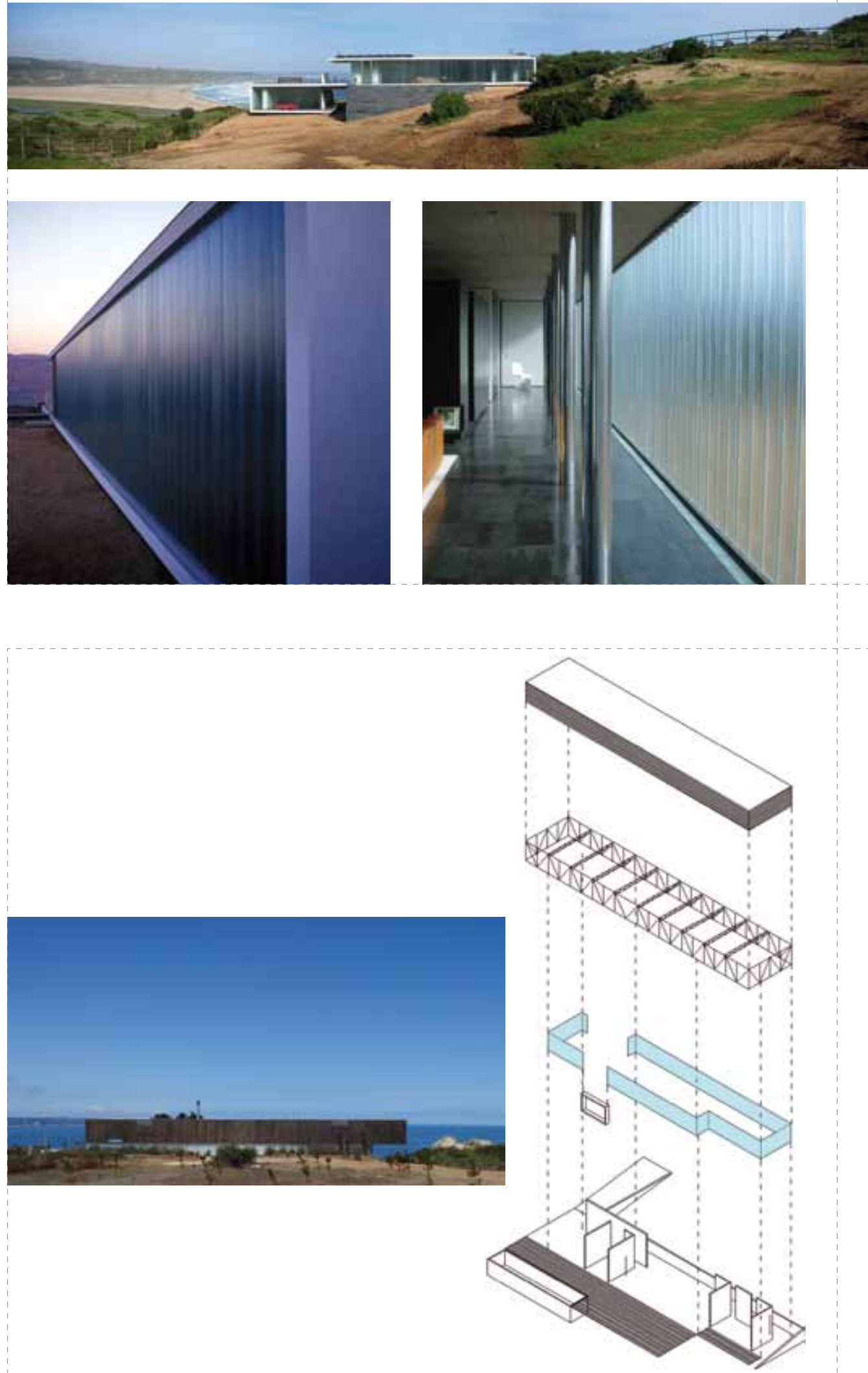

Casa Abrán, Tunquén. Albert Tidy + Ian Tidy, año 2005 (fotógrafo: Albert Tidy). 
Casa Schckolnick, El Arrayán. Albert Tidy + Ian Tidy + Hania Stambuk, año 2008.
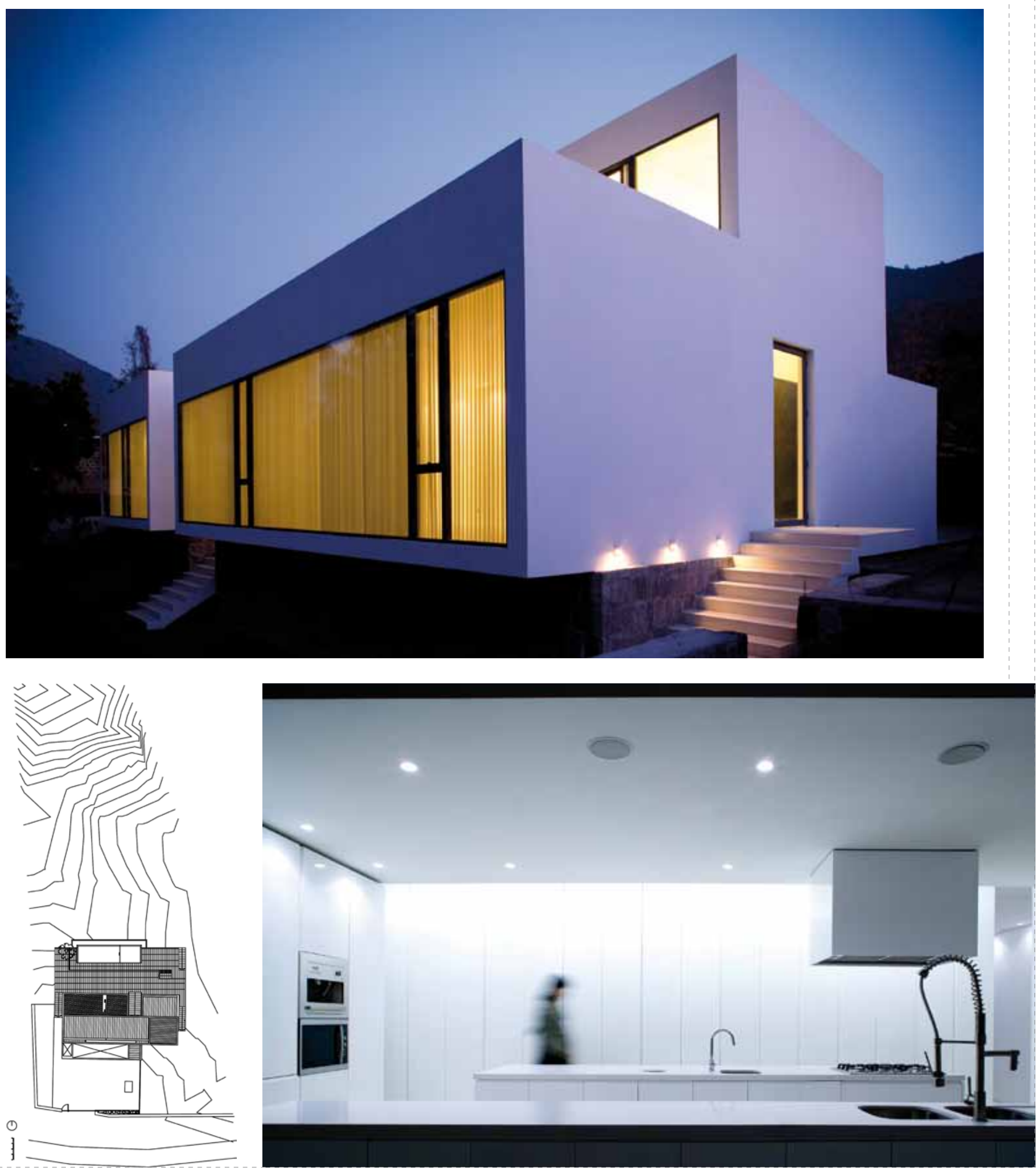

Entrevista a Tidy Arquitectos: Albert Tidy V. + Ian Tidy V. 
inconmensurable, pero es fácil en su lectura, y ahí radica su belleza.

Una vez materializada la obra, establecida su disposición y presencia en el escenario que la acoge. ¿De qué modo se propone el diálogo entre ésta y el territorio?

[AT]: Mientras más condensado y sintético el gesto, mayor será su impacto en el territorio.

[IT]: Pensamos que el diálogo entre la obra y el entorno es una consecuencia del hecho de existir. Ahora, es de esperar que este diálogo sea positivo, interesante, fluido y en el mejor de los casos potente. Creemos en el contraste como base de nuestra postura arquitectónica, y en la abstracción como medio de expresión del lenguaje.

También damos cabida a la intuición, tratamos de generar las causas para luego detectar los efectos inesperados, esas segundas lecturas que muestran sorpresas inesperadas que no estaban contempladas en el proyecto, ya que son consecuencia de un diálogo enriquecido por una obra que comienza a comunicarse con su entorno, aportando una postura clara y contrastante, muy lejos de querer mimetizarse.

Finalmente y pensado en la proyección del trabajo de la Oficina de cara al futuro, ¿hacia dónde apuntan las búsquedas conceptuales de su trabajo, en qué pie se encuentra la idea de síntesis como mecanismo de respuesta?

[IT]: Creemos que la idea de síntesis se encuentra en un punto de partida y que hemos avanzado sólo lo suficiente para darnos cuenta que es un recurso aparentemente inagotable. Así como puedes tomar el telescopio más avanzado, y mirar el universo sin encontrar un límite, también puedes hacer la acción inversa tomando un microscopio para explorar células, luego moléculas, átomos, etc. En este sentido creemos en la síntesis como medio de exploración ilimitado.

[AT]: lan tiene razón y la respuesta está ilustrada magníficamente en el corto de Charles y Ray Eames: Potencia de $10^{3}$.

3 Power of Ten. Charles \& Ray Eames, 1977
Casa Martínez, Laguna Aculeo Albert Tidy + Ian Tidy, año 2008 (fotógrafo: Cristian Barahona).
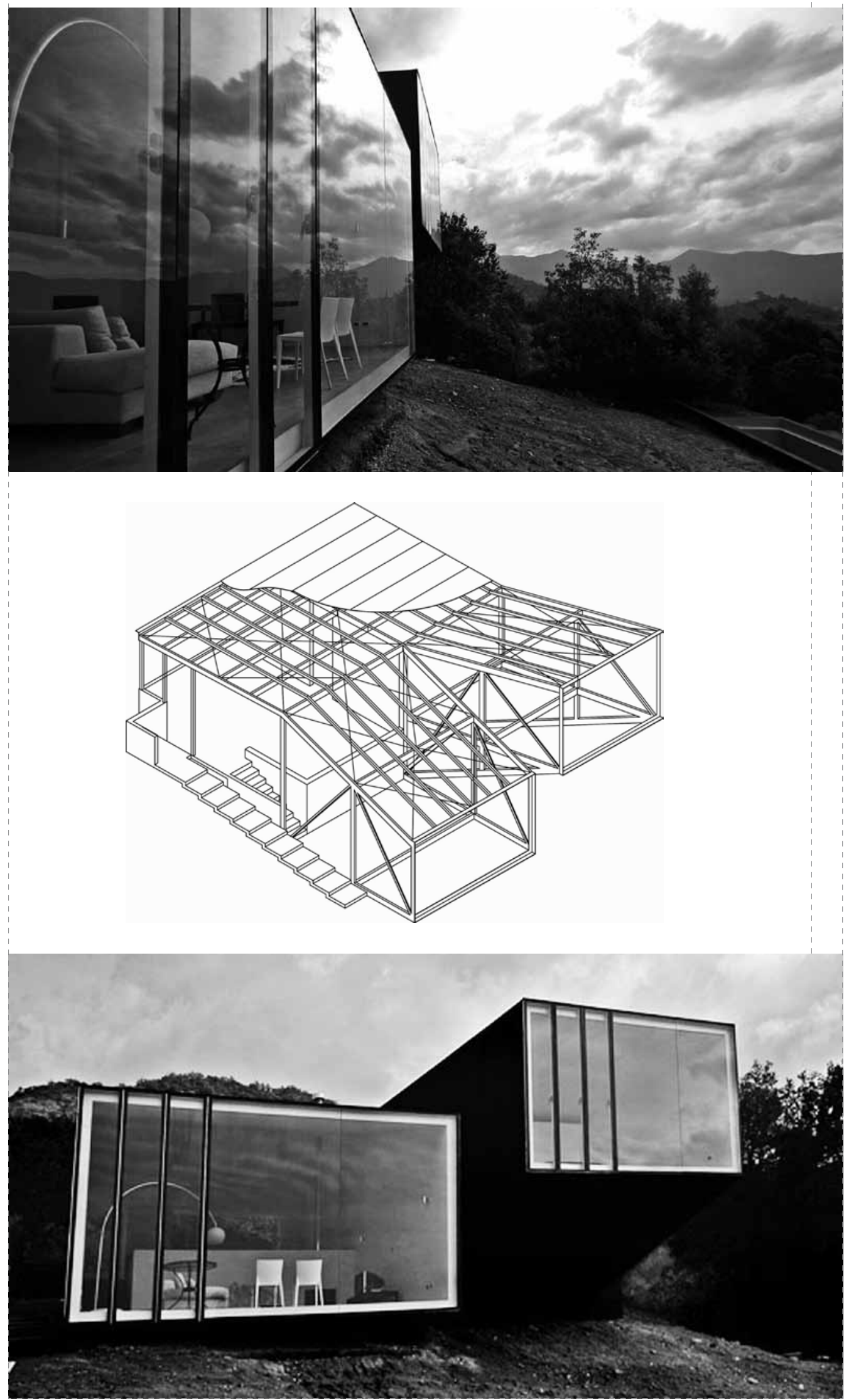
Casa Álvarez-Marshall, Chicureo. Albert Tidy + lan Tidy, año 2008 (fotógrafo: Marcelo Cáceres).
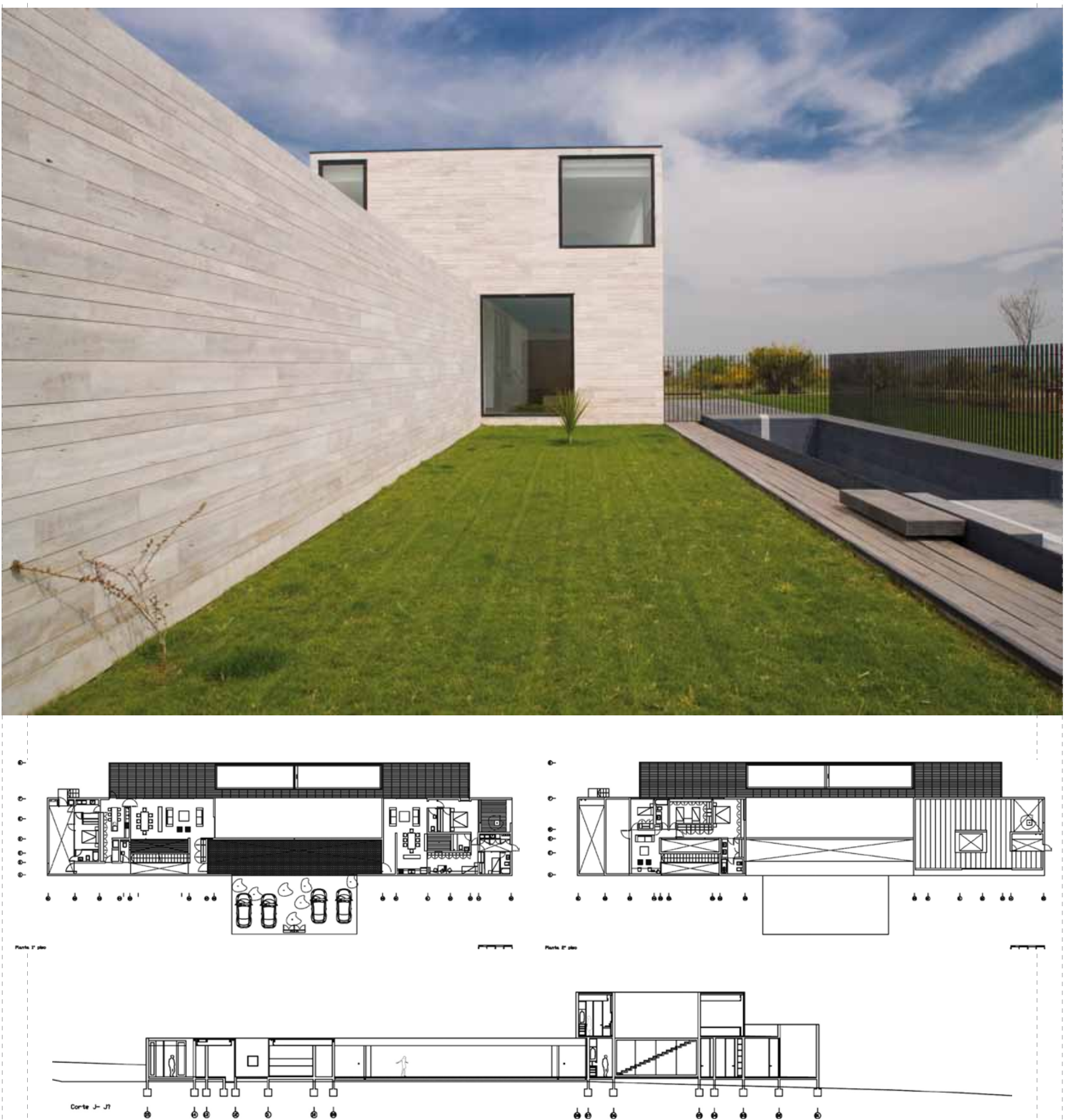